\title{
Research-Based Spin-Offs as Agents of Knowledge Dissemination: Evidence From the Analysis of Innovation Networks
}

\author{
Oscarina Conceição ${ }^{1}$, Cristina Sousa ${ }^{2}$ and Margarida Fontes ${ }^{3}$ \\ ${ }^{1}$ DINÂMIA'CET-IUL, University Institute of Lisbon, Lisbon, Portugal \& Polytechnic Institute \\ of Cávado and Ave, Barcelos, Portugal \\ 2ISCTE_IUL, University Institute of Lisbon, Lisbon, Portugal \& DINÂMIA'CET-IUL, University \\ Institute of Lisbon, Lisbon, Portugal \\ ${ }^{3}$ LNEG - National Laboratory of Energy and Geology. Lisbon, Portugal \& DINÂMIA'CET-IUL, \\ University Institute of Lisbon, Lisbon, Portugal \\ oconceicao@ipca.pt \\ cristina.sousa@iscte.pt \\ margarida.fontes@Ineg.pt
}

\begin{abstract}
The paper addresses the role played by research-based spin-offs (RBSOs) as knowledge dissemination mechanisms, through their position in knowledge networks. For this purpose the paper analyses the formal networks established by the Portuguese RBSOs in the context of publicly funded research, technology and pre-commercial product development projects, and investigates their configuration along two levels. At organisational level, in order to understand whether RBSOs extend their reach beyond the academic sphere; and if they do, whether they relate with similar firms or connect to organisations located downstream in the knowledge value chain, and which is their position in networks involving both research organisations and other firms. At spatial level, in order to understand whether RBSOs extend their reach beyond the region where they are created, thus potentially acting as connectors between diverse regions. The analysis starts from the population of RBSOs created in Portugal until 2007 (387) and identifies those that have established formal technological relationships as part of projects funded by all the programmes launched in the period 1993-2012. As a result, the analysis encompasses 192 collaborative projects and involves 82 spin-offs and 281 partners, of which only 20\% are research organisations, the remaining being other firms and a variety of other user organisations. The results, although still preliminary, provide some insights into the knowledge networking behaviour of the RBSOs. As expected, research organisations are a central actor in spin-offs' networks, being the sole partner for some of them. But half of the RBSOs have moved beyond the academic sphere, being frequently a central element in tripartite technological relationships between research and other organisations and occupying an intermediation position in the network, thus potentially acting as facilitators in knowledge circulation and transformation. Also as expected, RBSOs are predominantly located in the main metropolitan areas and tend to relate with organisations similarly located. But while geographical proximity emerges as important in the choice of partners, in about half of the cases, RBSOs knowledge networks have extended beyond regional boundaries. Given their central position in the network this suggests a role as connectors across regions that will be explored in subsequent research.
\end{abstract}

Keywords: spin-offs, knowledge networks, space; knowledge dissemination, inter-firm relationships

\section{Introduction}

In the last decades universities have been increasingly engaged in technology transfer activities, introducing a variety of policies to encourage and support the initiatives of their staff and students. Among these activities assume particular relevance the creation of research-based spin-off firms (RBSOs), which are regarded as generating value from academic research and, simultaneously, contributing to increase universities' reputation (Mustar et al, 2008; Perez and Sanchez, 2003; Wright et al, 2007).

The extension of the spin-off phenomenon, first in the US and then in Europe, led to the emergence of a stream of literature that addressed these firms' behaviour (Mustar et al, 2006). Research has was namely addressed the impact of RBSO on economic development, in particular at a regional level (Bathelt et al, 2010; Buenstorf and Geissler, 2011). However, it can be argued that RBSOs effective impact is not likely to be fully captured by traditional indicators such as employment or turnover. Given the nature of their activities and the intermediate position they often occupy between academic research and the market (Autio, 1997; Fontes, 2005), RBSOs impact is more clearly expressed through the value they create in knowledge and innovation networks, as agents of knowledge acquisition, transformation and diffusion (Harrison and Leitch, 2010; Perez and Sanchez, 2003; Walter et al, 2006). 
While this distinctive function of RBSOs is acknowledged in the literature, empirical research on its performance, beyond the creation process, is still limited. Moreover, research tends to focus on the relations between RBSOs and the "parent" (or other research organisations) (Heblich and Slavtchev, 2013; Semadeni and Cannella, 2011) and to put special emphasis on firms regional embeddedness and influence (Huggins and Johnston, 2009; Breznitz et al, 2008). But much less is known regarding RBSOs knowledge interactions with other firms (directly or as intermediaries from other knowledge sources), and on their role as knowledge conveyers across regions.

The objective of this paper is to address this gap, contributing to understand whether RBSOs are effectively acting as knowledge dissemination mechanisms through their position in knowledge networks, and which is the reach of their activities. For this purpose, the paper investigates the knowledge networks established by RBSOs, at two levels. At organisational level, to understand whether firms extend their reach beyond the academic sphere; and if they do, whether they relate with similar firms or reach to organisations located downstream in the value chain, thus potentially performing a wider role as knowledge disseminators. At spatial level, to understand whether firms extend their reach beyond the region where they are created, thus potentially acting as connectors between diverse regions.

For this purpose we conduct an analysis of the formal knowledge networks established by Portuguese RBSOs in the context of publicly funded collaborative research, technology and product development projects, between 1993 and 2012. The data encompasses the known population of RBSOs created in Portugal until 2007 and all the relevant funding programmes. The analysis addresses the configuration of the formal knowledge networks formed in the context of these projects, focusing on both partner composition and location, in order to assess their organisational and spatial reach (overall and for specific industries). The results provide some indications towards the extent and nature of RBSOs knowledge impacts.

\section{From academia to industry - the role of spin- offs}

Research-based spin-offs (RBSO) have been found to play an important role as knowledge transfer mechanisms (Bathelt et al, 2010; Helm and Mauroner, 2007). In fact, RBSOs are set-up to commercially exploit the results of academic research, transforming it in technologies, products or services and making them accessible to the society. Moreover, if successful in their endeavour, RBSOs are likely to continue acting as sources and disseminators of new knowledge over time.

\subsection{The nature of RBSOs technological relations: "bridging" between organisations?}

For analytical purposes it is possible to consider two mains stages in the transfer process enacted by RBSOs. One that involves the interaction between the research organisation and the new firm to support the further development of the knowledge that is being commercialised as part of the spin-off process, or to joint-develop new or complementary knowledge in areas relevant for the firm. Another that involves the search for and interaction with potential users of the technology or its applications, in order to gain a better understanding of market needs and requirements and, eventually, to access complementary competences and resources. Although the latter are more frequently related with business and market development, relationships may also concern the development of new technological knowledge in areas that are critical for the success of the innovation and that go beyond the spin-off frequently specialised competences (Colombo et al, 2006).

These stages can overlap, i.e. these processes may take place simultaneously in the context of tripartite relationships that involve research organisations, spin-offs and other firms. Research conducted on this type of alliance has found evidence of a certain division of work (Stuart et al, 2007). For instance, Hess et al (2013), based on a series of case studies, concluded that, in industry alliances between spin-offs, industry and academic partners, the different members had well-defined roles in the innovation process. In fact, product needs, market access and industrialisation ability were brought into the alliance by the industry partner, while the spin-off brought technology know-how, as well as and its academic network, which provided access to laboratories and relevant technology talent.

The effectiveness of RBSO as "bridges" between academia and the industry depends on entrepreneurial actions, such as opportunity identification, risk taking, resource mobilisation that can be more effectively achieved through networks (Grandi and Grimaldi, 2003; Walter et al, 2006). However, despite the extensive literature on the role of networks in technological entrepreneurship (Elfring and Hulsink, 2003; Slotte-Kock and Coviello, 2010) there is still limited research on the nature of the relationships that are established as part of the 


\section{Oscarina Conceição, Cristina Sousa and Margarida Fontes}

"bridging" process. At this level, the literature tends to focus on the interaction between the spin-off and the parent organisation (Audretsch and Lehmann, 2005; Colombo et al 2006; Heblich and Slavtchev, 2013; Semadeni and Cannella, 2011) giving less attention to the downstream relationships established with other types of organisations to further develop and commercialise the technology. Among these, technological relationships that is, those concerned with completing the development of technologies (that are often in a very incipient stage), with defining product and/or process requirements and with conducting product development activities, prior to commercialisation - which are likely to require a set of technological competences located downstream from academic research, are particularly absent, despite their relevance for this type of firm.

It is nevertheless relevant to point out that the need for and the intensity of the technological relationships and the composition of resulting knowledge networks can vary between firms. In fact, it has been shown that the patterns of interaction between academy and industry depend on the scientific field (Schartinger et al, 2002). Similarly, the configuration of knowledge networks established by new technology intensive firms have been found to differ between industries (Salavisa et al, 2012). These differences are likely to be pertinent in the case of RBSOs, which are not necessarily a homogeneous group (Cunha et al, 2013), affecting their need to maintain collaboration with research organisations, and the intensity and type of technological relationships they establish with downstream organisations.

Considering the above, it is possible to raise the following research questions, in what concerns the composition of the knowledge networks established by RBSO.

- Are technological relationships mostly established with the parent research organisation, or involve also other organisations located downstream?

- When networks involve downstream organisations are RBSO mostly part of tripartite relationships, also involving research organisations?

- Are these knowledge networks more frequent in some industries / technology fields?

\subsection{The location of RBSOs partners: Connectors between regions?}

RBSOs tend to be located in clusters, usually in large cities with a high business concentration, thereby benefiting from agglomeration economies, i.e. positive externalities resulting from co-location (Audretsch and Feldman, 2004; Buenstorf and Geissler, 2011). Location in metropolitan areas also reflects the importance assumed by the proximity to major universities in gaining access to knowledge spillovers, which is often facilitated by the personal networks of academic entrepreneurs (Conceição et al, 2014; Heblich and Slavtchev, 2013). In fact spinoffs tend locate in the vicinity of the parent organisations, with which they often retain close relationships, at least in the early years (Lemarie et al, 2001; Kolympiris, 2015).

Overall, spin-offs location in metropolitan areas favours the development of a wider network of relationships, which positively influences their performance (Audretsch and Feldman, 2004; Capello 2006). For instance, van Geenhuizen et al (2014), comparing the spin-offs population of two universities located in different environments found that those located in core metropolitan areas benefit from a more diverse network compared those in more isolated cities. The heterogeneity of the networks (e.g. demographic, geographical and management diversity) has also been found to have a positive effect on knowledge transfer (Cummings, 2004). However, there was less attention to an eventual cross-regional scope of these networks, in particular to whether RBSOs, which tend to be located in areas with greater knowledge concentrations, connect to organisations located in other regions.

Considering the above, it is possible to raise the following research questions in what concerns the spatial reach of the knowledge networks established by RBSOs.

- Are RBSO knowledge networks more frequently composed of organisations located in the main metropolitan areas?

- Do RBSOs establish technological relationships preferably with organisations located in the same region? 


\section{Data and method}

\subsection{Data sample: The Portuguese RBSOs}

The analysis uses a self-collected dataset composed of the population of RBSOs created in Portugal until 2007, totalling 327 firms. RBSOs are defined as firms created by individuals who have some stable connection with a university or other research institution, such as faculty members, researchers and graduate students, and who are applying knowledge obtained or technology developed as part of their activity; and firms created by external entrepreneurs based on the transfer of technology developed by a research organisation.

The first firm was created in 1979, but the number of spin-offs only started to increase in the 1990s and effectively took off in the 2000s (54.13\% were created after 2000). These firms tend to be created in the main metropolitan areas where the most prestigious universities are located. In fact, $52 \%$ of the spin-offs are located in municipalities belonging to the districts of Lisbon (the capital with 30\%) and Porto (the second city with 22\%) followed at a certain distance by the districts of Coimbra, Braga and Aveiro.

\subsection{Knowledge networks: Data and analysis}

To identify the formal knowledge networks established by the RBSOs, the paper draws on data on collaborative projects conducted in Portugal in the context of all public programmes funding both research and precompetitive technology and product development and/or demonstration activities. Given RBSOs reliance on public funding for research and development activities (Wright et al, 2007), this data is expected to offer a good coverage of the formal relationships established by these firms in this domain.

The data was obtained from the Innovation Agency (AdI) database and covers the period 1993-2012. All projects with spin-off involvement were identified and data was collected on the characteristics of each project and on the partners involved. The data was treated in order to harmonize organisations' names (e.g. the same organisation would appear named by its acronym and by its full name). Then, the organisations were characterised along three dimensions: location, type of organisation and area of activity.

A total of 192 projects have been identified, involving 82 RBSOs, corresponding to representing about $1 / 4$ of the spin-off population. The vast majority (82\%) had participated in 1 to 3 projects. But two spin-offs, both in the ICT industry and origination from the same university (Coimbra), had a disproportionately high number of participations (respectively 17 and 21 projects).

Collaborative projects constitute two-mode networks that link organisations to an event - the projects. From these we have extracted a one-mode network, considering inter-organisational networks, where a tie joins two organisations, if they collaborate in the same project. We have built symmetric adjacency matrices, valued by the number of common projects and conducted Social Network Analysis (SNA), using UCINET software. The diagrams were obtained with NetDraw software.

From the vast set of SNA measure we will focus our attention on: i) the size of the network, in terms of number of actors and ties; ii) the network composition, in terms of the share of each type of partner; iii) the positioning of actors, assessing their centrality and their role as cut-points. Centrality measures enable to detect more favourable network positions, namely in terms of access to the most relevant knowledge sources (Powell, Koput and Smith-Doerr, 1996). In this paper two different centrality measures are used: degree centrality enabling to capture those actors that are more active in the network; and betweenness centrality enabling to capture those actors that lie between the various other organisations. Cut-points are actors who have a pivotal significance in holding the network together (Scott, 2000) and may act as brokers among otherwise disconnected groups.

\section{Portuguese RBSO knowledge networks}

\subsection{Network composition and the role of actors}

The knowledge network of Portuguese RBSOs is represented in Figure 1. The network consists of 363 organisations, of which 23\% are RBSOs, $14 \%$ are research organisations (including universities and independent research centres, both public and private non-profit), $55 \%$ are other firms and $8 \%$ are a variety of other organisations, with a predominance of business associations, regional agencies and other collective 


\section{Oscarina Conceição, Cristina Sousa and Margarida Fontes}

organisations. In the subsequent analysis this last group is merged with the "Other firms", since conceptually both are technology users, i.e., downstream organisations. The network is formed by a large component (involving about $96 \%$ of the network actors and $94 \%$ of the RBSO) and by 5 small components that reflect the individual networks of five RSBOs.

A detailed analysis of the 192 formal technological collaborations reveals that in $50 \%$ of the projects the spinoffs established partnerships exclusively with ROs (Table 1). Among these, parent organisations have a prominent role: in half of the cases the RBSO parent is involved in the collaboration and in $1 / 4$ of the projects it is the only partner. As would be expected, research organisations (RO) are important actors in the network. In fact, more than $3 / 4$ of the projects involve at least one RO and, despite their relatively low share in the total number of network actors (14\%), they occupy very central positions in the network, both in terms of degree and in terms of betweenness (Figure 2).

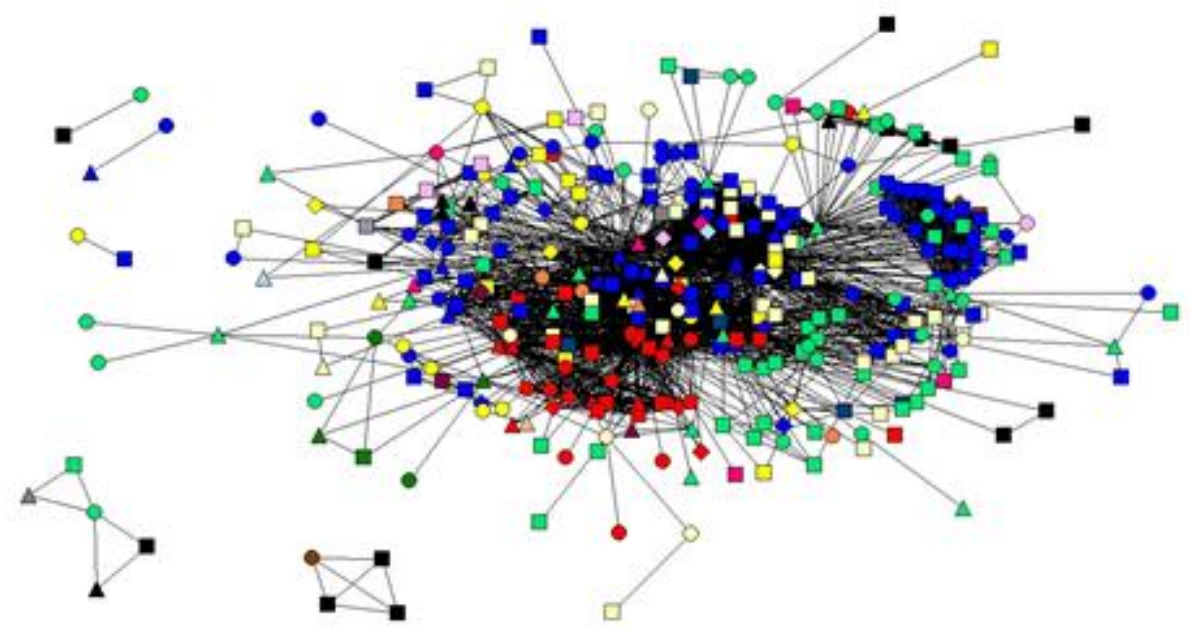

Legend: Shapes represent organisation type: Spin-offs - circle; Firms - square; Research organisations - triangle; Other - diamond. Colours represent organisation location (district): Lisboa - Light green; Porto - Blue; Coimbra Red; Braga - Yellow; Aveiro - Light yellow; Beja - Purple; Bragança - Light orange; Castelo Branco - Orange; Évora - Light blue; Faro - Green; Leiria - Dark blue; Santarém - Light pink; Setúbal - Pink; Viana do Castelo - Violet; Vila Real - Light grey; Viseu - Dark grey; Madeira - Brown; Foreign - Black.

Figure 1: Portuguese RBSO knowledge network

a) Degree

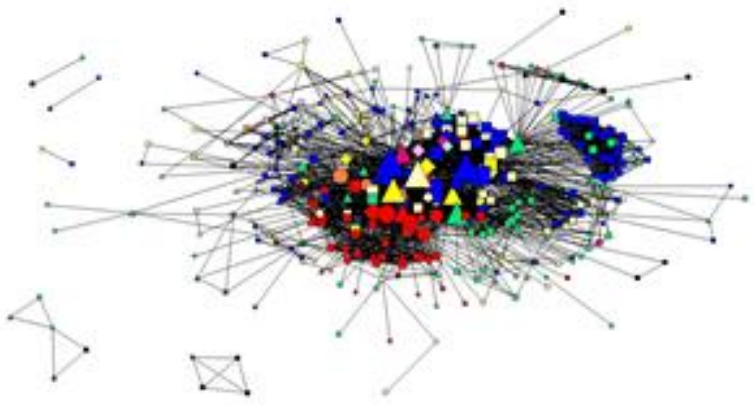

b) Betweenness

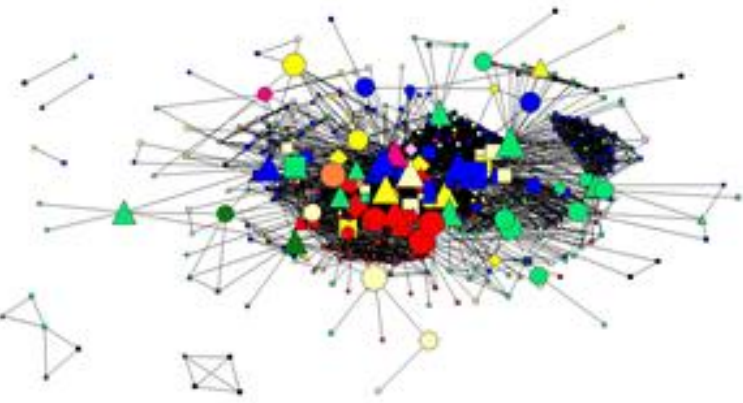

Legend: Identical to Figure 1 . The size of the node reflects the actor centrality.

Figure 2: Actor centrality

Table 1: Distribution of teams - projects composition $(n=192)$

\begin{tabular}{|c|c|c|}
\hline Team & Number & Percentage \\
\hline Spin-offs + Research organisations & 96 & 50.00 \\
\hline Spin-offs + Downstream organisations & 33 & 17.19 \\
\hline Spin-offs + Research organisations + Downstream organisations & 63 & 32.81 \\
\hline Total & 192 & 100 \\
\hline
\end{tabular}

Source: Own calculations. 
The data also shows that in only a small number of projects (17\%) the spin-offs collaborate exclusively with other firms. But, in one third of the collaborative projects there is tripartite network, including spin-offs, research organisations and established firms (Figure 1). This result points to an intermediation role of RBSO in the network, which is further corroborated by the fact that RBSOs coordinate $77 \%$ of the projects identified. The same conclusion can be draw from the analysis of betweenness centrality (Figure $2 \mathrm{~b}$ and Table 2), where spinoffs (represented by circles) emerge as relevant actors. Actually, considering the first decile of the betweenness distribution, we observe that $1 / 3$ of the most central actors are RBSO. Organisations with a high betweenness appear frequently in the path between other organisations, enabling the circulation of knowledge between them. Moreover, RBSO appear as the most frequent type of organisation in the analysis of cut-points (Figure 3): half of the cut-points are RBSOs, the remaining being mostly research organisations $(46 \%)$.

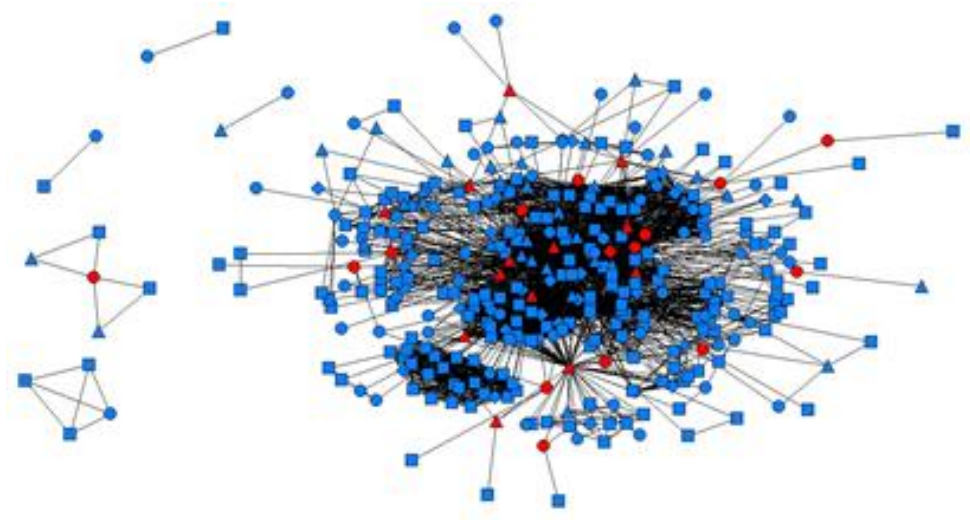

Legend: Shapes represent organisation type: Spin-offs - circle; Firms - square; Research organisations - triangle; Other - diamond.

Nodes In red represent the cut-points.

Figure 3: Network cut-points

Regarding the industry, the majority of collaborative projects identified involve RBSOs in biotechnology or ICT. However, considering the distribution of spin-offs' population by industry, it is possible to conclude that technological relationships are more frequently present among electronics firms and biotechnology firms (respectively $47 \%$ and $36 \%$ ). They are relatively less frequent among ICT and energy firms and almost inexistent in the remaining industries. In addition, among the firms that established formal technological relationships, the involvement of the parent organisation was also found to differ significantly across the technological area of the project: it is relatively higher in chemicals, biotechnology, agro-food and materials and relatively lower in the other areas, which include ICT and electronics. This suggests differences between RBSOS active in different industries, both regarding the need to establish technological relationships and the nature of the knowledge they search in these relationships (Salavisa et al, 2013).

\subsection{The localisation of actors}

The results show that spin-offs located in the metropolitan areas establish formal technological relationships more frequently (Table 2). Between 25 and $30 \%$ of the spin-offs located in the 5 main districts participated in collaborative projects, as compared with $16 \%$ of the spin-offs located in those with lower population density. Furthermore, when we analyse the location of the other organisations involved in the 82 projects, we conclude that those are equally the districts where RBSO partners are predominantly located (Table 3).

Table 2: Distribution of Portuguese RBSOs with formal networks by localisation ( $n=82$ )

\begin{tabular}{|c|c|c|c|c|c|}
\hline \multirow{2}{*}{ Districts } & \multicolumn{2}{|c|}{ Spin-offs in projects } & \multicolumn{2}{c|}{ Spin-offs Population } & \multirow{2}{*}{$\begin{array}{c}\text { Relative } \\
\text { frequency }\end{array}$} \\
\cline { 2 - 5 } & $\mathrm{N}$ & $\%$ & $\mathrm{~N}$ & $\%$ & 25.25 \\
\hline Lisboa & 25 & 30.49 & 99 & 30.28 & 28.17 \\
\hline Porto & 20 & 24.39 & 71 & 21.71 & 28.00 \\
\hline Coimbra & 14 & 17.07 & 50 & 15.29 & 23.68 \\
\hline Braga & 9 & 10.98 & 38 & 11.62 & 31.58 \\
\hline Aveiro & 6 & 07.31 & 19 & 05.81 & 16.00 \\
\hline Others & 8 & 09.76 & 50 & 15.29 & \\
\hline Total & 82 & 100 & 327 & 100 & \\
\hline
\end{tabular}

Source: Own calculations 
Table 3: Distribution of network partners by localisation

\begin{tabular}{|c|c|c|}
\hline Districts & $\begin{array}{c}\text { Number of } \\
\text { partners }\end{array}$ & $\%$ \\
\hline Lisboa & 77 & 21.21 \\
\hline Porto & 108 & 29.75 \\
\hline Coimbra & 43 & 11.85 \\
\hline Braga & 31 & 08.54 \\
\hline Aveiro & 44 & 12.12 \\
\hline Foreign & 18 & 04.96 \\
\hline Others ${ }^{1}$ & 42 & 11.57 \\
\hline Total & 363 & 100 \\
\hline
\end{tabular}

${ }^{1}$ Others relate to 12 Districts with less than 8 partners. Source: Own calculations.

The results also show that geographical proximity seems to be important in the establishment of these technological partnerships, since a large share of the projects involve partners in the same municipality and/or district (Table 4): $80 \%$ of the technological collaborations involve at least two partners in the same district, while in about $45 \%$ of the projects all partners are located in the same district. However, this data also show that more than half of the RBSOs also relate with organisations outside the municipality and even outside the district, suggesting that there may be knowledge circulation beyond the region where they are located. A more detailed analysis of the data will enable us to understand whether these links connect to organisations in the same type of region (i.e. the main metropolitan areas or others), as well as which type of organisations are involved in those cross-regional relationships.

Table 4: Proximity of network partners in each project $(n=192)$

\begin{tabular}{|c|c|c|}
\hline & Number & $\%$ \\
\hline At least two in the same district & 152 & 79.17 \\
\hline All in the same district & 88 & 45.83 \\
\hline At least two in the same municipality & 129 & 67.19 \\
\hline All in the same municipality & 70 & 36.46 \\
\hline
\end{tabular}

Source: Own calculations.

\section{Conclusions}

This paper presented the first results of an analysis of the formal technological relationships established by the population of Portuguese RBSOs, whose goal was to explore the role played by these firms in knowledge networks. In particular, we explored whether RBSOs effectively act as "bridges" between research organisations (in particular the parent) and organisations located downstream in the knowledge value chain; and whether they reach beyond the region where they are located. The results, although very preliminary, already offer some interesting insights and provide some directions for further research.

In what concerns the organizational reach of RBSO, the results show that, as would be expected, the parent research organisation is an important actor in most firms' knowledge networks. Moreover, half of the firms only establish formal technological relationships with research organisations, reproducing a frequently depicted pattern among RBSOs. However, the other half has also established relationships with non-academic organisations, and a still substantial number emerge as a central element in tripartite technological relationships. Furthermore, when considering the network formed by the RBSO and its partners, several spinoffs are found to occupy a position as brokers between the other network actors, potentially facilitating the circulation of knowledge across them. Subsequent research, addressing the evolution of these relationships over the RBSOs life, will investigate whether the structure of the relationships and the position and role of RBSOs change over time.

In what concerns the regional reach of RBSOs, the results confirm that they are predominantly located in the main metropolitan areas and, overall, tend to relate with similarly located organisations. Moreover, most firms establish technological relationships with at least some partners located in the same district, or even in the same municipality. But, although a still substantial number of firms are exclusively connected with organisations in the vicinity, there is also a number of RBSOs that establish technological relationships across municipal or even district boundaries, suggesting a broader network scope. Subsequent research will address in greater detail the 
composition of these extra-regional networks, in order to understand whether RBSOs are acting as conveyers of knowledge across regions and, in particular, between the metropolitan areas where they predominantly locate and less munificent ones.

Finally, the analysis has focused exclusively on projects funded by national programmes, which usually only encompass national organisations (although a few foreign partners were identified). However, it is our contention that a full assessment of the role of RBSOs in knowledge networks requires also the consideration of their eventual international technological relationships (Capaldo et al, 2015). Subsequent research will therefore extend the analysis to include also the projects funded by European programmes.

\section{References}

Audretsch, D. and Feldman, M. (2004) Knowledge spillovers and the geography of innovation, in: Henderson V, Thiesse JF (eds) Handbook of regional and urban economics. Elsevier: 2713-2739.

Audretsch, D. and Lehmann, E. (2005) "Does the knowledge spillover theory of entrepreneurship hold for regions?", Research Policy, Vol. 34, pp 1191-1202.

Autio, E. (1997) “New, technology-based firms in innovation networks symplectic and generative impacts", Research Policy, Vol. 26, pp 263-281.

Bathelt, H., Kogler, D. and Munro, A. (2010) "A knowledge-based typology of university spin-offs in the context of regional economic development", Thecnovation, Vol.30, pp 519-532.

Breznitz, S., O'Shea, R. and Alan, T. (2008) "University Commercialization Strategies in the Development of regional Bioclusters", Journal of Product Innovation Management, Vol. 25, pp 129-142.

Buenstorf, G. and Geissler, M. (2011) "The origins of entrants and the geography of German laser industry", Papers in Regional Science, Vol. 90, pp 251-270.

Capello, R. (2006) Regional Economics. London: Routledge.

Capaldo, G., Fontes, M., Rippa, P., Cannavacciuolo, L. and Sousa, C. (2015) “Networks mobilized to access key resources at early stages of biotech firms: A comparative analysis in two moderately innovative countries", European Planning Studies, Vol. 23, pp 1381-1400.

Colombo, M., Grilli, L. and Piva, E. (2006) “In search of complementary assets: the determinants of alliance formation of high-tech start-up”, Research Policy, Vol. 35, pp 1166-1199.

Conceição, O., Faria, A. P. and Fontes, M. (2014) Entry by research-based spin-offs: the determinants of regional variation, in I. Bernhard (Ed.) Geography and Innovation. The Frequency, Nature and Consequences of Entrepreneurship and Innovation in Regions de Varying Density, Trollhättan: University West, pp: 205-224.

Cummings, J. (2004) "Tie and network correlates of individual performance in knowledge-intensive work", Academy of Management Journal, Vol. 47, No. 6, pp 928-937.

Cunha, D., Silva, S. and Teixeira, A. (2013) “Are Academic Spin-Offs necessarily New Technology-Based firms" FEP Working Papers, n. 482, Faculdade de Economia da Universidade do Porto.

Elfring, T. and Hulsink, W. (2003) "Networks in Entrepreneurship: The case of high-technology firms", Small Business Economics, Vol. 21, pp 409-422.

Fontes, M. (2005) "The process of transformation of scientific and technological knowledge into economic value conducted by biotechnology spin-off", Technovation, Vol. 25, pp 339-347.

Grandi, A. and Grimaldi, R. (2003) "Exploring the networking characteristics of new venture founding teams", Small Business Economics, Vol. 21, No. 4, pp 329-370.

Harrison, R. and Leitch, C. (2010) "Voodoo Institution or Entrepreneurial University? Spin-off Companies, the Entrepreneurial System and Regional Development in the UK", Regional Studies, Vol. 44, No. 9, pp 1241-1262.

Heblich, S. and Slavtchev, V. (2013) "Parent universities and the location of academic startups", Small Business Economics, Vol. 42, pp 1-15.

Helm, R. and Mauroner, O. (2007) "Success of research-based spin-offs. State of the art and guidelines for futher research", Review of Managerial Science, Vol. 1, No. 3, pp 237-270.

Hess, S., Suhrbeer, S. and Siegwart, R. (2013) "The impact of collaborative innovation between established industry and academic technology spin-offs", Business and Management Research, Vol. 2, No. 3, DOI:10.5430/bmr.v2n3p1

Huggins, R. and Johnston, A. (2009) "The economic and innovation contribution of universities: a regional perspective", Environment and Planning C: Government and Policy, Vol. 27, pp 1088-1106.

Kolympiris, C. Kalaitzandonakes, N. and Miller, D. (2015) "Location choice of academic entrepreneurs: Evidence from the US biotechnology industry", Journal of Business Venturing, Vol. 30, pp 227-254.

Lemarié, S., Mangematin, V. and Torre, A. (2001) "Is the creation and development of biotech SMEs localised? Conclusions drawn from the French case", Small Business Economics, Vol. 17, pp 61-76.

Mustar, P., Renault, M., Colombo, M., Piva, E., Fontes, M., Lockett, A., Wright, M., Clarysse, B. and Moray, N. (2006) "Conceptualising the heterogeneity of research-based spin-offs: A multi-dimensional taxonomy", Research Policy, Vol. 35, pp 289-308.

Mustar, P., Wright, M. and Clarysse, B. (2008) "University spin-off firms: lessons from ten years of experience in Europe", Science and Public Policy, Vol. 35, No. 2, pp 67-80. 
Perez, M. and Sanchez, A. (2003) "The development of university spin-offs: early dynamics of technology transfer and networking”, Technovation, Vol. 23, pp 823-831.

Powell, W., Koput, K. and Smith-Doerr, L. (1996) "Interorganizational collaboration and the locus of innovation: networks of learning in biotechnology", Administrative Science Quarterly, Vol 41, No. 1, pp 116-145.

Salavisa, I., Sousa C. and Fontes, M. (2012) "Topologies of innovation networks in knowledge-intensive sectors: sectoral differences in the access to knowledge and complementary assets through formal and informal ties" Technovation, Vol. 32, No. 6, pp 380-399.

Schartinger, D., Rammera, C., Fischer, M. M. and J. Fröhlich (2002) "Knowledge interactions between universities and industry in Austria: sectoral patterns and determinants", Research Policy, Vol.31, pp 303-328.

Scott, J. (2000) Social Network Analysis - A Handbook. $2^{\text {nd }}$ Edition. London: Sage.

Semadeni, M. and Cannella, A. (2011) "Examining the performance effects of post spin-off links to parent firms: should the apron strings be cut?", Strategic Management Journal, Vol. 32, pp 1083-1098.

Slotte-Kock, S. and Coviello, N. (2010) "Entrepreneurship Research on Network Processes: A Review and Ways Forward", Entrepreneurship Theory and Practice, Vol. 34, No. 1, pp 31-57.

Stuart, T. E., Ozdemir, S. Z. and Ding, W. W. (2007) "Vertical alliance networks: the case of university-biotechnologypharmaceutical alliance chains", Research Policy, Vol. 36, pp 477-498.

van Geenhuizen, M., Taheri, M. and Soetanto, D. (2014) “Triple Helix Interaction: Importance of Spin-off Firms' Networks and the University as Partner" ", in: Proceedings of the Asia Triple Helix Society Summer Seminar, 25 June 2014, Daegu South-Korea.

Walter, A., Auer, M. and Ritter, T. (2006) "The impact of network capabilities and entreprenueurial orientation on university spin-off performance", Journal of Business Venturing, Vol. 21, pp 541-567.

Wright, M., Clarysse, B., Mustar, P. and Lockett, A. (2007) Academic Entrepreneurship in Europe. Cheltenham: Edward Elgar. 